\title{
“A DANÇA DA SOLIDÃO”: A CONDIÇÃO NARRATIVA EM SOLIDÃO CONTINENTAL, DE JOÃO GILBERTO NOLL
}

\author{
Ivana Ferigolo \\ Universidade do Estado do Mato Grosso \\ ivanaferigolo@hotmail.com
}

"Desilusão, desilusão danço eu dança você na dança da solidão".

(Paulinho da Viola)

\section{RESUMEN / RESUMO / ABSTRACT}

El escritor brasileño João Gilberto Noll viene siendo reconocido tanto en Brasil como en el exterior debido a su particular poética, consolidada a partir de una amplia producción narrativa que comienza en 1980, con la publicación del libro de cuentos $O$ cego e a dançarina, y que se mantiene muy fértil hasta el presente. En la opinión del estudioso argentino Reinaldo Laddaga (2007), João Gilberto Noll es uno de los autores que ha publicado las obras literarias más singulares producidas en los últimos años no solo en América Latina. Esa singularidad presentada por la literatura de Noll ha despertado, al parecer, la atención de los críticos y engendrado muchos estudios que se encuentran materializados en un volumen significativo de tesis, tesinas, libros, artículos, ensayos, etc. En este amplio repertorio de estudios es posible constatar posicionamientos divergentes sobre la producción literaria del autor. Muchos confieren valor significativo a su obra, considerando positivo el grado de innovación que presenta en relación con expresivos comportamientos manifestados por el género novela a lo largo de la modernidad. No faltan, sin embargo, opiniones que aseguran la falta de identificación de las narrativas del autor con el género novela, debido a ciertas particularidades formales y temáticas. Considerando la singularidad de la producción narrativa nolliana y tomando como objeto de análisis su última novela, Solidão continental (2012), se busca entender lo que esta singularidad estaría expresando, así como averiguar los impactos de esa singularidad sobre el campo literario brasileño.

PALABRAS ClAVE: literatura brasileña, novela, sujetos, contemporaneidad. 
O escritor brasileiro João Gilberto Noll vem sendo conhecido tanto no Brasil como no exterior devido a uma particular poética, que se encontra bem sedimentada em uma volumosa produção narrativa emergente em 1980, com a publicação do livro de contos $\mathrm{O}$ cego e a dançarina, e que se mantém fértil até o presente. Nos dizeres do crítico argentino Reinaldo Laddaga (2007), João Gilberto Noll é um dos autores que tem publicado, nos últimos anos, algumas das produções literárias mais singulares já vistas não só na América Latina. Essa singularidade apresentada pela literatura de Noll tem chamado a atenção da crítica literária e alavancado uma forte tendência ao estudo de sua obra traduzida em um volume significativo de teses, dissertações, livros, artigos, ensaios, etc.. Nesse vasto repertório de estudos críticos, é possivel encontrar posicionamentos divergentes sobre a obra do autor. Muitos conferem valor significativo a essa produção literária, considerando positivo o grau de inovação que apresentaria em relação a expressivos comportamentos exibidos pelo gênero romance ao longo da modernidade. Outros tendem a olhá-la com desconfiança, argumentando que, devido a particularidades formais e temáticas, essas narrativas já não poderiam ser consideradas romances. Levando em conta a singularidade da produção narrativa nolliana e tomando como objeto de análise o último romance do autor, Solidão continental (2012), busca-se compreender o que estaria expressando, no concernente ao homem e à vida, esta singularidade narrativa. Além disso, pretende-se entender o que significa essa singularidade da narrativa de Noll para o campo literário brasileiro.

PaLAVRAS-ChaVE: literatura brasileira, romance, sujeitos, contemporaneidade.

The Brazilian writer João Gilberto Noll is well known both in Brazil and in other countries because of his particular poetry, built into a copious narrative production that emerged in 1980 with the publication of the collection of stories O Cego e a Dançarina, and which continues to be highly fertile even now. In the opinion of the Argentine scholar Reinaldo Laddaga (2007), João Gilberto Noll is one of the writers who has published some of the most innovative narratives seen in recent times, and not only in Latin America. The singularity of Noll's literature has attracted the attention of critics and has spawned many studies that have been published in a significant volume of theses, books, articles, papers, etc. In this extensive body of critical studies there are divergent positions on Noll's literature. Many of them attribute significant value to Noll's literary production considering the degree of innovation that shows to be positive in relation to the more expressive behavior displayed by the novel genre throughout modernity. However, there are many other critics who argue that the lack of identification of Noll's narratives with the novel genre is due to certain formal and thematic peculiarities. Considering the singularity of Nollian narrative production and studying his last novel, Solidão Continental (2012), we seek to understand what this singularity could be expressing and examine the impacts of this singularity on the field of Brazilian literature.

KEYWORDS: Brazilian narrative, subject, novel, contemporaneity. 


\section{UMA POÉTICA NOLLIANA}

O escritor brasileiro João Gilberto Noll, desde os anos 80, quando foi publicada sua primeira obra, o livro de contos $O$ cego e a dançarina, passa a chamar a atenção de estudiosos e críticos em virtude da particularidade de sua narrativa, que, desde o princípio, agradava muitos setores da crítica literária, mas, também, causava, em outros, o natural estranhamento suscitado por fenômenos ou artefatos artísticos inovadores. Na atualidade, após ter publicado um número bem significativo de narrativas como Hotel Atlântico, O quieto animal da esquina, A céu Aberto, Harmada, Berkeley em Bellagio, Lord, Acenos e Afagos, para citar algumas, o autor goza de importante reconhecimento nacional e internacional a ponto de muitos estudiosos e críticos, como é o caso do argentino Reinaldo Laddaga, afirmarem que "João Gilberto Noll, que nació en Porto Alegre, ha estado publicando algunos de los objetos textuales auténticamente singulares que hayan visto la luz en los años recientes en Latinoamérica (y no solamente, en rigor, en Latinoamérica)" (79).

A singularidade narrativa, nas palavras do crítico argentino, é o detalhe diferenciador da produção literária de Noll e, ao que parece, tem despertado a curiosidade de estudiosos originando, nos últimos anos, um volume significativo de estudos traduzidos em teses, dissertações, livros, artigos, ensaios, etc. É nos elementos constitutivos da narrativa nolliana, como tempo, narrador, personagem, espaço, tema, que poderemos visualizar essa singularidade destacada por Laddaga (79).

Avulta e recorrente nas obras de Noll é uma temporalidade fragmentada, em que passado, presente e futuro aglutinam-se, sobrepõem-se, desconectamse, desorientando o leitor, que enfrenta a impossibilidade de perceber as ligações entre os fatos e as ações constitutivas da existência das personagens e conformadoras do mundo da representação.

Os espaços predominantes em suas obras são, em geral, os que o antropólogo francês Marc Augé (71-105) chamou de não lugares (ruas, rodoviárias, aeroportos, cidades, shoppings, hospitais, etc.), ou seja, os cenários que viabilizam e sustentam os deslocamentos curtos e transnacionais que caracterizam a existência produzida e reproduzida nesse ambiente contemporâneo, denominado por Augé (71-105) de Supermodernidade. Trata-se de espaços esvaziados de sentido, vagos, comuns, recorrentes, carentes do potencial de estranhamento necessário ao desencadeamento de gestos de aferição, de análise e de reflexão. Transitando por esses não lugares quase imperceptíveis, dada à mesmice recorrente e desorientadora que os caracteriza, e inclinados a um 
constante deslocamento que oblitera a possibilidade de percepção da própria existência como uma continuidade conexa, os personagens das narrativas de Noll, conforme Avelar, passam, em geral:

por experiências desprovidas de qualquer marco temporal, além da sucessão esquizofrênica, não causal dos fatos, [...] obtém e perdem empregos, são presos ou levados a algum hospital [...], escapam, são atacadas [...], encontram gente que não parece ir a nenhum lugar tampouco, e que invariavelmente desaparece sem deixar rastros (217).

Outro traço a se destacar nas narrativas de Noll é o fato de serem narradas em primeira pessoa. Predominam narradores protagonistas que, sugerindo a impossibilidade de conhecer o outro e o mundo e transparecendo um desejo de ser visto ou notado, adotam uma postura ensimesmada, tentando narrar a própria existência que somente vem à tona em fragmentos desconexos, incapazes de constituir uma totalidade. No contato com essas narrativas, o leitor é assaltado por um estranhamento que parece decorrer da sugestiva ausência de motivos capazes de costurar ou evidenciar as relações entre as partes que constituiriam a vida das personagens. Dessa forma, a produção ou o desvelamento do sentido da existência, meta central do romance ao longo da modernidade, fica comprometida nas narrativas de Noll.

Os narradores protagonistas, em geral, mostram-se conscientes da ausência de uma lógica existencial ou cósmica profunda ou sobre a impossibilidade do sujeito desvendá-la. A consciência sobre as limitações do sujeito em relação à apreensão de um sentido imanente ao mundo e à vida ou sobre a inexistência do mesmo se evidencia em quase todas as narrativas de Noll, fazendo-se visível de variadas maneiras, principalmente na presença de indagações que povoam os relatos, mas ficam suspensas. Os narradores protagonistas as lançam, mas, logo, as deixam de lado, não tratam de respondê-las. São questionamentos, muitas vezes, que dão origem ao processo narrativo como é o caso da obra Berkeley em Bellagio (2002), cujo princípio se constitui pelas seguintes indagações: "Saberia voltar atrás? Não se arrependeria ao ter de mendigar de novo em seu país de origem?" (Noll, Berkeley 9). Dito relato de Noll não coincidirá, porém, com o resultado de uma tentativa de deslindar uma resposta para essas questões, sugerindo que o mote das narrativas nollianas não é responder, encontrar ou "comunicar significados estabilizados, estados de ánimo fijados o estados de cosas sustanciales" (Laddaga 84).

Nesse aspecto, os relatos do referido escritor brasileiro estabelecem distância em relação a um comportamento central manifestado pelo gênero 
romance desde sua projeção nos albores da modernidade e conservado posteriormente. Aquele comportamento que, traduzido em formas variadas e até fragmentadas, como é, por exemplo, o caso de No caminho de Swann, de Proust, sempre se caracterizou pela busca de sentido ou por tentativas de encontrar as ligações entre os diversos eventos constitutivos da vida ou de uma dada condição social, cósmica ou existencial.

Aparentando, ainda, um descompromisso com o social, as narrativas de Noll acabam rompendo, também, com uma tendência narrativa que predominou durante dois séculos no Brasil: o romance realista e, muitas vezes, de inclinação empenhada que, colocando em evidência um vasto repertório de agravantes sociais, pretendia desvelar soluções plausíveis aos problemas da nação e contribuir, pela via estética, para o melhoramento do país e da condição do seu povo. Nesse sentido, conforme sugere Avelar, os romances de Noll se apresentam como "uma crítica ao romanção, às maquinarias narrativas cosmogônico-totalizantes que encontraram seu apogeu na Comédia humana, de Balzac, modelo privilegiado para as várias sagas realistas, regionalistas ou não que proliferaram na literatura brasileira moderna" (216).

O potencial de ruptura que abrigam as narrativas de Noll em relação a modalidades romanescas bem expressivas (tanto a nível nacional como internacional) se faz notório, incitando a delimitação de gestos hermenêuticos dispostos a esclarecer os motivos que as levam a se distanciar de certos modelos romanescos bem consolidados. Partindo da hipótese de que esse distanciamento decorre de uma inclinação da produção literária de Noll em dar forma tanto a modos de existência bem contemporâneos (que transcendem os limites do nacional) como aos efeitos produzidos por eles sobre os homens e sobre suas relações com o mundo e com os outros, analisar-se-á, a seguir, o último romance de Noll, Solidão continental (2012). Pretende-se, ainda, deslindar os possíveis efeitos para o gênero romance e para o campo literário brasileiro, que se originariam dessa suposta tendência da literatura de Noll pela formalização de experiências humanas vinculadas aos tempos atuais.

\section{SOLIDÃO CONTINENTAL: UM EFEITO DA URGÊNCIA EXISTENCIAL}

Em Solidão continental (2012), último romance de João Gilberto Noll, se constata a permanência da tendência narrativa do autor, de forma que a singularidade de sua poética mencionada por Laddaga (79) fica reforçada. O romance põe em cena, por meio de um processo narrativo em primeira pessoa, 
fragmentos existenciais do narrador protagonista que sugere chamar-se João Bastos, já que, quando lhe exigem sua identificação ele deixa transparecer, no relato, uma dificuldade de memória, titubeando no momento de afirmar seu nome próprio.

Trata-se de um protagonista de nacionalidade brasileira, que já viveu fora do país, nos Estados Unidos, mas que, em algum momento, pois não há especificação temporal, retorna para Porto Alegre, fazendo, no percurso da volta, uma escala no México. Afetado por uma inquietude que dificulta sua fixação em determinados lugares, o narrador protagonista se desloca constantemente (USA, México, Brasil), vivenciando, de forma muito rápida, uma infinidade de fatos que, devido a curta durabilidade, não sobrevivem como memória e, consequentemente, não se mostram propensos a serem revisitados, resgatados ou reaplicados posteriormente. A narrativa, consequentemente, despe-se de relações causais. Os fatos têm validade isoladamente, não registrando qualquer ligação lógica. A possibilidade de conformação de um sentido a partir das relações entre os fragmentos ou as cenas que dizem respeito à vida do protagonista e que compõem a narrativa, fica comprometida.

Da estada do protagonista nos USA, a narrativa privilegia fatos que tiveram lugar em ruas, hotéis e em uma escola de idiomas, onde, supostamente, o protagonista trabalhou. No México, permaneceu, ao que parece, pois não há especificação precisa no relato, umas doze horas, devido a uma escala feita pelo avião em decorrência de problemas mecânicos. Durante esse período, sem justificativa clara, visita o museu de Trótski, onde encontra uma menina com a qual mantém relações sexuais. Em Porto Alegre, seu deslocamento é constante. Ruas, shoppings, bairros desconhecidos e até bosques de localização geográfica imprecisa servem de vias para o frequente deslizar do protagonista.

Transitando por esses não lugares (Augé 71-105) -típicos da sociedade atual denominada pelo autor francês de Supermodernidade- que regulam o deslocamento dos seres e promovem contatos rápidos, o narrador protagonista tem amenizada a capacidade de memorizar e refletir. As ações que realiza, consequentemente, despem-se de justificativa. Surgem como corolário de uma espécie de impulso carente de um planejamento ou de intenções pautadas em lembranças, conhecimentos ou reflexões. A visita feita ao museu de Trotski, durante a escala forçada do avião no México, vem à tona como uma decisão apoiada em informações rasas que o protagonista não filtra, nem questiona: "Guardei a mala no aeroporto. Pedi ao taxista que me levasse ao Museu de Trotski. [...] Poderia no intervalo entre um voo e outro ter ido visitar outro museu. Vim, pelo que me contaram, ao menos espetacular" (Noll, Solidão 40- 
41). O esfacelamento do sujeito enquanto razão reflexiva vai se evidenciando no relato e parece decorrer da inserção do protagonista em um meio marcado pelo trânsito intenso e por uma volumosa circulação de informações que aceleram o funcionamento de sua mente e de seu ritmo existencial dificultando ou impedindo o desencadeamento de qualquer processo de contemplação, de meditação e de reflexão.

Em seus constantes deslocamentos, o protagonista se depara com situações inusitadas, encontra repentina e rapidamente diversas personagens, que, em função da brevidade dos contatos, se mostram estranhas, impenetráveis, realizam ações incompreensíveis tanto ao protagonista como ao leitor. Essa obscuridade das personagens fica evidente em um fragmento em que o protagonista revela ter saído, sem aparente motivo, com Tom, um suposto aluno de português nos USA, o qual, repentinamente e sem motivo constatável, tira a roupa:

No meio da lascívia meio submersa eu reiterava a dúvida se isso não fazia parte de um plano para ele espionar em mim as virtudes e pecados de um brasileiro médio. Eles se infiltravam em relações pessoais com indivíduos de outros países, para levar a seus chefes a quanto andava a alma do mundo. [...] Depois de uma aula em que ensinei o mais que perfeito composto, ele me convidou a passear no domingo, iríamos até um lago nos arredores de Madison. E fomos (Noll, Solidão 29).

A maneira de contar presente no fragmento e predominante na narrativa, é altamente econômica. Processos descritivos, qualificativos, são deglutidos pela ênfase dada à ação. Fatos e detalhes são atropelados e a ordem cronológica do relato alterada em decorrência da aceleração mental revelada pelo narrador. O gesto, o convite que desencadeou o suposto passeio de Tom e do protagonista é o último dado mencionado no fragmento, sinalizando que a mente do narrador opera apressadamente e inviabiliza tanto a organização dos fatos de forma linear e ascendente, como a fixação do narrador em detalhes capazes de revelar conexões entre os acontecimentos relatados. O laconismo e a velocidade do relato fazem da existência protagonista um conjunto de vivencias rápidas e repentinas que impossibilitam tanto o conhecimento dos outros com quem ele estabelece contato, como a compreensão dos fatos em que ele se envolve. Consequentemente, Tom (o outro com quem o narrador passeia) ganha uma feição enigmática, insondável, permitindo, unicamente, a suspeita, a dúvida (eu reiterava a dúvida...). 
O que põe em cena a narrativa Solidão continental são vivências e impressões sobre o homem e sobre o mundo atreladas a um modo de vida efêmero, típico de seres em constante deslocamento ou errância, como é o caso do narrador protagonista, que não é norte-americano, está em trânsito, e carece, portanto, do tempo necessário para o estabelecimento de laços duradouros tanto com ambientes como com objetos e pessoas. A consequência dessas relações efêmeras, traduzidas em um discurso acelerado, conciso, que ofusca os contornos das personagens, tornando-as meras palavras de origem e destino encobertos, é uma existência marcada pela constante dúvida, pela suspeita frente ao outro, pela impossibilidade de conhecer, de constituir vínculos duradouros, de sentir confiança, de partilhar e trocar experiências, de estabelecer relações de cumplicidade. Uma existência propensa a abrigar, portanto, a sensação de vazio, de solidão, já que fica negada ao ser a possibilidade de se fundir ao outro ou ao meio, de experimentar a totalidade. E como indica o título, essa solidão é continental, generalizada, atinge o ser em todas as partes, levando o narrador protagonista a desejar, continuamente, o contato, a companhia, o convívio mais duradouro, a atenção:

[...] o certo é que andava louco para enfim me acercar de duas, três pessoas, ou nem tanto assim, que se interessassem pelo que eu comera no almoço, por exemplo, e uma pelo menos que estivesse disposta comigo, nem digo que trocasse comigo seus fluidos, mas que indagasse como fora meu sono, que confessasse que ouvira meu ronco só ao amanhecer... (Noll, Solidão 41).

Ganham visibilidade, em Solidão continental, as faltas e as consequências existenciais atreladas a estilos de vida bem contemporâneos, peculiares à sociedade globalizada, essa que, segundo Augé (71-105), viabiliza o trânsito, o deslocamento constante, originando ritmos de vida acelerados, que impedem a fixação geográfica dos seres, podendo inviabilizar a conformação de laços ou sentimentos duradouros. Que consequências são essas? A solidão aguda que experimenta o protagonista dada dificuldade de conhecer o outro; a sensação de vazio decorrente, conforme assinalou Fredric Jameson no clássico Pós-modernismo: a lógica cultural do capitalismo tardio (1997), da impossibilidade de reter o passado e convertê-lo em memória reaplicável no presente.

Essa dificuldade de sedimentação da experiência passada em conhecimento, em memória resgatável, a qual provoca o esvaziamento do ser, se faz evidente na estrutura de Solidão Continental. A obra compõe-se de dois grandes 
blocos desconexos. O primeiro, que se encerra na página 47 , concentra as vivências do narrador protagonista registradas nos USA e no México. O segundo bloco, compreendido entre a página 48 e a final, põe em cena a desconexa existência do protagonista após seu retorno a Porto Alegre. Essas duas partes não apresentam ligação. O passado nos USA e a breve passagem no México não são recuperados pelo protagonista durante sua fase em Porto Alegre. Uma única vez, no que denominados segundo bloco do livro, o narrador protagonista faz alusão a esse período de sua vida para afirmar: "As minhas viagens pelos Estados Unidos e México eram coisas do passado" (Noll, Solidão continental 69). Na falta de nexo entre essas duas partes da narrativa visualiza-se descontinuidade entre passado e presente registrada pelo narrador protagonista, um corte que torna sua existência fragmentada, que lhe desorienta, lhe esvazia, forçando-lhe a inventar a vida a toda instante, a submeter-se a riscos que lhe permitam sentir alguma coisa, a buscar algo que lhe complete, mesmo ciente da não existência dessa "coisa" (Noll, Solidão continental 84) ou da impossibilidade de alcançá-la: "Antes que seja tarde demais eu preciso instalar em mim velocidade [...] Não para fugir de nada. Mas para tentar encontrar o que só com urgência se desvelaria. Como o quê? Não sei, não enche o saco!, tartamudeei” (Noll, Solidão 57).

A irritação do protagonista consigo mesmo acusa sua percepção sobre a inexistência ou a inacessibilidade desse "algo" que possa preencher sua vida. Essa consciência, embora lhe imprima uma constante sensação de vazio, funciona como um estímulo que o leva a agir, a buscar, mesmo sabendo que não encontrará. No gesto de procurar, vê-se a resistência do protagonista a experimentar o nada, mesmo consciente de que não poderá vencê-lo. Esse vazio, que requer um preenchimento contínuo, decorre da própria condição errante do protagonista, da rapidez com que se desenvolvem e terminam as relações entre ele e as demais personagens, da volatilidade dos contatos, da velocidade com que troca de ambiente. A celeridade dá o tom à sua existência e oblitera a possibilidade de ele processar suas vivências, retê-las, refletir sobre elas, entendê-las, conhecer o entorno, internalizar referências, preencher-se a partir das experiências, como atesta o seguinte fragmento em que o protagonista relata sua saída do México, que compreende o deslocamento do Museu de Trotski, visitado no breve período em que ele passa no país, até o aeroporto:

Um taxi providencial passava. Chamei. Ele parou. Sentei atrás. No caminho para o aeroporto minha cabeça caiu várias vezes de exaustão. Passei no hotel para pegar a valise. 
Corria pelo aeroporto atrás do balcão da companhia aérea. Peguei um novo cartão de embarque. Entrei no avião com uma profusão de coisas na cabeça. Bill, Tom, Mira, o que me sobrara de tudo aquilo? (Noll, Solidão 47).

A consequência dessa aceleração imposta por condições existenciais marcadas pelo trânsito constante é o rápido apagamento do passado. Uma abundância de vivencias, de "coisas" na cabeça fadadas à liquefação antes de serem sedimentadas. Como ele próprio admite em outros momentos da narrativa, seu "ritmo mental se fazia em voragem. De um golpe eu concebia o passado, como se ele estivesse ainda por se fazer. Eu me ressentia por não ter como provocar meu futuro por livre escolha. Entre um e outro eu era reticências, desse impasse era feito meu presente" (Noll, Solidão 63). Assim, Mira, a menina com a qual manteve uma rápida e fugaz relação sexual no museu de Trotski, Bill, o ex-amante que procura quando está nos USA, Tom, o exsoldado americano que conhece na escola de idiomas nos Estados Unidos tornam-se meras palavras sujeitas à esfumação ou ao apagamento.

Na pergunta sobre o que sobrara desse passado, constata-se a angustia do narrador protagonista frente ao vazio instalado pela impossibilidade de sedimentação mental de vivências ou experiências sensíveis. Essa angustia acusa a falta registrada pelo protagonista e o coloca frente à necessidade do urgente preenchimento dessa lacuna mental que não retém o passado, nem ao menos divisa o futuro. A urgência força-o a se manter constantemente em movimento, em estado de busca. Busca algo para preencher esse vazio propulsor de solidão. "[...] procuro a cada canto à cata da coisa que me completará nos próximos instantes" (Noll, Solidão 84). Admite que se "enfezava com qualquer coisa que [...] prometesse desmontar [...] a solidão" (Noll, Solidão 60).

É com movimento, deslocamento, e não mediante reflexão ou fixação, que o protagonista busca suprir, a cada instante, a sensação contínua de vazio e solidão emergentes da impossibilidade de sentir, de recordar, de fixar o passado e convertê-lo em experiência. Como o que procura não pode forjar-se pela aceleração, pelo movimento, já que a efemeridade impede a fixação das vivências, dificulta a possibilidade de sentir ou de estabelecer vínculos duradouros, sua busca contínua e exaustiva reinstala o vazio, colocando-lhe novamente em errância, reconduzindo-lhe a ruas escuras, a florestas desconhecidas, ao contato repentino com outros seres que nem chegam a tomar forma de tão rápido que aparecem e desaparecem. A rapidez com que tudo se estabelece e se dissolve, com que tudo passa pela vida do 
narrador protagonista desfigura, esvazia os espaços e as demais personagens reposicionando-lhe em seu estágio de partida: o vazio e a solidão.

O que a narrativa coloca em cena é a saga errante e intransponível do homem contemporâneo, desse ser, que nos dizeres de Octávio Paz, habita o universo estilhaçado, fragmentado, movediço e carente de utopias que toma feição no ocidente do pós-guerra. Trata-se de um ambiente em que "o tempo se torna descontínuo. E o mundo, o todo se desfaz em pedaços" (Paz 75), provocando a "dispersão do homem errante em um espaço que também se dispersa, errante em sua própria dispersão" (Paz 75).

Conformando-se de forma acelerada, as ações de busca empreendidas pelo protagonista tornam-se fugazes, repromovendo o seu contato com o nada, com um entorno desfigurado, esvaziado, fantasmagórico, impenetrável. A "coisa" capaz de preenchê-lo nunca é encontrada. O que se mantém é o corte entre o eu vazio de sentido e o mundo. Evidencia-se, por meio do relato, a impossibilidade da fusão entre o eu e o mundo, definida por Lukács (25-163) como totalidade e apontada pelo autor como mote central do gênero romance. A narrativa põe em cena, assim, a impossibilidade de manifestação do sujeito em um entorno geográfico e humano volátil, que impede o exercício do pensamento, da observação, da memória, da reflexão e do desenvolvimento afetivo duradouro. Indica que, nesse contexto, a "dispersão errante" (Paz 75) é a amarga e insuperável condição do ser. Na perda da capacidade de refletir, de se fixar, de sentir, de recordar apresentada pelo protagonista e na sua falida busca de sentido através da urgência, do trânsito, estampa-se o desmantelamento do sujeito. A morte do sujeito enquanto razão reflexiva (marcada, também, por densidade afetiva) e a contínua e angustiante sensação de solidão despontam, na obra Solidão continental, como os efeitos (sobre o homem) ocasionados por um entorno formado por não lugares como o contemporâneo que, promovendo e estimulando o deslocamento constante dos seres, se desdobra aos seus olhos de forma superficial, fragmentada, distorcida, levando-lhes a um estado de dispersão e de vazio.

É com um aspecto surreal, fantasmagórico, que os espaços se projetam sobre o olhar do protagonista como é possível constatar em um fragmento em que ele narra o resultado de uma de suas investidas pela busca de uma companhia que viesse aliviar sua solidão. Nessa empreitada, o protagonista, de forma repentina, urgente, impulsiva, convida um marceneiro desconhecido e sua esposa para jantarem juntos. O casal retribui o convite. A casa do marceneiro e de sua mulher fica em um bairro retirado da cidade e os fundos dão a uma espécie de bosque. Após uma fulminante passagem pela casa do 
marceneiro, os três entram em uma floresta. Nesse novo cenário, contatado de forma rápida e inesperada, tudo, segundo o narrador protagonista, "se dissolvia para uma espécie de afastada dimensão: estava aí o palacete onde moravam numa riqueza assustadoramente irreal" (Noll, Solidão 54).

A rapidez que caracteriza os contatos do protagonista com outros e com as diversas partes da cidade, traduzida em um discurso apressado, portador de lapsos temporais, desfigura os espaços, rouba-lhes a densidade e a impressão de realidade. A urgência de sua busca, decorrente do esvaziamento provocado por um estilo de vida frenético, recoloca o protagonista sempre em contato com esse ambiente estranho e saturado da cidade, o qual não lhe oferece nada. Na fragmentada, desorientada e esvaziada existência do protagonista, evidenciam-se as consequências humanas de um modo de vida apressado e forjado em ambientes urbanos que tendem, segundo Santos:

a ser um "lugar nenhum", quase um "vazio" de percepção [...] que, pelo alto grau de saturação, torna impossível qualquer enraizamento, qualquer identificação. Espaço intangível que produz um estado de suspensão do vínculo entre o indivíduo e o que está ao seu redor, que gera a experiência da própria dissolução dos limites da individualidade. Espaço de formas excessivas e oscilantes que torna recíprocas as tendências de irreconhecer o mundo e de irreconhecer-se (132).

Nas buscas falidas do protagonista de Solidão continental se estampa a dramática e insolúvel condição do homem (des)ambientado em um contexto saturado, móvel, urgente, de feição intangível, como o da atualidade: trata-se de uma condição de errância que, não conduzindo a nada, encurrala o ser, dando-lhe como última e única alternativa uma procura vazia, circular e intranscendente como a prática de Sísifo, que tem validade somente enquanto processo. Solidão continental materializa, dessa forma, a falta de saída existencial registrada pelo ser submetido a um modo de vida cujos principais efeitos humanos são, segundo Jameson (1997), a míngua da possibilidade de sentir, de recordar, de projetar o futuro, de estabelecer vínculos perenes, de se sentir protegido, de proteger, conhecer e reconher o outro.

\section{O SENTIDO DO NARRAR EM SOLIDÃO CONTINENTAL}

O esfacelamento da capacidade de sentir é levado ao extremo em Solidão continental (2012). A narrativa materializa angústias humanas, põe em 
evidência a morte do sujeito, a impossibilidade de reconstituição da totalidade do ser, mas não sugere uma saída, não oferece solução alguma: as buscas do protagonista não o conduzem a superação do vazio, nada se conclui, nenhuma relação se fixa, o passado não supre o presente. O relato é fruto de uma consciência que acusa o nada e revela unicamente o nada. Esse vazio apresenta-se em cada aventura inconclusa do narrador protagonista e sugere a impossibilidade de seu preenchimento diante do esfacelamento do sujeito, da memória e da presença de um mundo que se mostra intangível.

Se o relato não leva a nada e é fruto de uma consciência que acusa a impossibilidade de alcance dessa "coisa" capaz de viabilizar a superação da solidão, do vazio, cabe perguntar qual o sentido desse gesto de narrar. Denunciar o vazio e driblá-lo, ao menos momentaneamente, mediante o jogo, a dança construída a partir das palavras. Dança da solidão, cujo sentido está no dançar, ou seja, nesse narrar que, materializando o apressado e constante ritmo do protagonista pelas fantasmagóricas pistas formadas pelos não lugares, evita a queda no vazio. Na busca deslizante e, de antemão falida, do protagonista por companhia, por atenção, ou seja, por sinais humanos que amenizem a sua solidão, se visualiza a resistência do ser frente a um mundo que perdeu a densidade, tende a se esvaziar de sentido e a registrar a míngua do humano. $\mathrm{Na}$ atitude de seguir narrando, mesmo sabendo que a criação não poderá oferecer sinais de superação, vê-se, por sua vez, a resistência do romance, que chama o leitor a perceber o vazio existencial e o esfacelamento humano.

A narrativa de Noll sugere, portanto, que a vida nos moldes atuais (marcada pela velocidade e (des)ambientada nos não lugares) não preenche o sujeito e nisso expressa um vínculo com uma sensibilidade contemporânea que ultrapassa os limites do nacional (Brasil). Ela materializa a angústia do ser, as mazelas decorrentes de um modo de vida que se produz pela lógica apressada e frenética que rege e garante a manutenção da produção e do consumo desenfreados. Traduz, assim, a luta da narrativa para fazer frente ao estabelecido em tempos difíceis, em tempos de apagamento do humano, da míngua do sujeito e da rarefação ou morte das grandes utopias.

Essa luta encontra-se materializada em um narrador que procura, como não acontecia em nenhuma outra narrativa do próprio autor Noll, a cura da solidão, que reivindica companhia ou a presença do outro. Levar o leitor a visualizar os doloridos efeitos existenciais de uma vida submetida à errância e a volatilidade, tal como se apresenta a vida contemporânea, é o mote central dessa narrativa. Esse elemento a torna herdeira do gérmen crítico e de denúncia que alimenta a literatura moderna e que foi bem incorporado pelo romance 
desde os albores da modernidade. Mesmo sendo gestado por uma consciência incapaz de vislumbrar uma saída para o angustiante esvaziamento do sujeito, o romance segue narrando, ao menos para sensibilizar o leitor, para convidálo a olhar a vida a partir de lentes que exibem as negativas consequências existenciais de um entorno vendido como o espaço da liberdade, da conexão total e planetária. Pôr em evidência os doloridos efeitos de formas de vida bem atuais é o grande propósito de Solidão continental, uma finalidade que viabiliza a continuidade do narrar, que leva a literatura brasileira a trilhar caminhos diferentes dos percorridos pela forte e tradicional vertente realista que, já no século XIX, ocupava um lugar de destaque no campo literário brasileiro ${ }^{1}$.

\section{BIBLIOGRAFIA}

Augé, Marc. Não-lugares: introdução a uma antropologia da supermodernidade. Campinas: Papirus, 1994.

Avelar, Idelber. Alegorias da derrota: a ficção pós-ditatorial e o trabalho de luto na América Latina. Belo Horizonte: Editora UFMG, 2003.

Jameson, Fredric. Pós-modernismo: A lógica cultural do capitalismo tardio. São Paulo: Ed. Atica, 1997.

Laddaga, Reinaldo. Espectáculos de realidad: ensayo sobre la narrativa latinoamericana de las últimas dos décadas. Rosario: Deatriz Viterbo Editora, 2007.

Lukacs, Georg. A teoría do romance. São Paulo: Duas Cidades; Editora 34, 2009.

Noll, João Gilberto. Solidão continental. Rio de Janeiro: Record, 2012. Berkeley em Bellagio. São Paulo: Francis, 2003.

Paz, Octavio. Signos em rotação. São Paulo: Perspectiva, 1972.

Santos, Luis Alberto Brandão. "Textos da cidade". 1000 rastros rápidos: cultura e milênio. Coord. Maurício Salles Vasconcellos; Haydée Ribeiro Coelho. Belo Horizonte: Autêntica, 1999. 131-138.

1 Este artigo corresponde à ampliação e à redefinição de um texto escrito para ser publicado no Caderno de Cultura do Jornal Diário da Serra, de Tangará da Serra, MT, Br. Seu primeiro esboço foi apresentado, de forma oral, no XIV SILEL, ocorrido em Uberlândia - Br em novembro de 2013. 